\title{
Environmentally Conscious Closed-Loop Aqueous and Semi-Aqueous Cleaning Systems for Defluxing and Degreasing
}

Federal Manufacturing \& Technologies
M. D. Smith and
G. W. Christoff

KCP-613-5757

Published March 1996

Final Report on Cooperative Agreement

Number 93-KCPP-019-E1, Project 04138300,

Between the Department of Energy, Kansas City Plant, and American Technical Ceramics, Huntington Station, New York

Approved for public release; distribution is unlimited. 


\section{DISCLAIMER}

This report was prepared as an account of work sponsored by an agency of the United States Government. Neither the United States Government nor any agency thereof, nor any of their employees, makes any warranty, express or implied, or assumes any legal liability or responsibility for the accuracy, completeness, or usefulness of any information, apparatus, product, or process disclosed, or represents that its use would not infringe privately owned rights. Reference herein to any specific commercial product, process, or service by trade names, trademark, manufacturer, or otherwise, does not necessarily constitute or imply its endorsement, recommendation, or favoring by the United States Government or any agency thereof. The views and opinions of authors expressed herein do not necessarily state or reflect those of the United States Government or any agency thereof.

Printed in the United States of America.

This report has been reproduced from the best available copy.

Available to DOE and DOE contractors from the Office of Scientific and Technical Information, P. O. Box 62, Oak Ridge, Tennessee 37831; prices available from (615) 576-8401, FTS 626-8401.

Available to the public from the National Technical Information Service, U. S. Department of Commerce, 5285 Port Royal Rd., Springfield, Virginia 22161.

A prime contractor with the United States Department of Energy under Contract Number DE-ACO4-76-DP00613.
AlliedSignal Inc. Federal Manufacturing \& Technologies P. O. Box 419159 Kansas City, Missouri 64141-6159 
KCP-613-5757

Distribution Category UC-706

Approved for public release; distribution is unlimited.

\title{
ENVIRONMENTALLY CONSCIOUS CLOSED-LOOP AQUEOUS AND SEMI-AQUEOUS CLEANING SYSTEMS FOR DEFLUXING AND DEGREASING
}

\author{
M. D. Smith and \\ G. W. Christoff \\ Published March 1996
}

Final Report on Cooperative Agreement Number 93-KCPP-019-E1, Project 04138300, Between the Department of Energy, Kansas City Plant, and American Technical Ceramics, Huntington Station, New York 


\section{FINAL ABSTRACT}

A Cooperative Agreement was initiated between American Technical Ceramics (ATC) Corporation, One Norden Lane, Huntington Station, New York, a manufacturer of ceramic chip capacitors for the electronics industry, and the Department of Energy (DOE), Kansas City Plant (KCP). (The KCP is operated by AlliedSignal Inc., Federal Manufacturing and Technologies, for the United States Department of Energy under Contract No. DE-ACO4-76-DP00613.) The purpose of this project was to develop an environmentally conscious closed-loop cleaning process which would meet the cleaning needs of ATC, reduce worker exposure to hazardous chemicals, and eliminate or reduce their hazardous waste.

In order to accomplish this, new cleaning materials needed to be tested for cleaning efficacy as compared to trichloroethylene. The project work plan was broken down into five phases including establishing a baseline cleaning level, evaluating alternative cleaners, specifying and purchasing closed-loop cleaning equipment, installing and evaluating the new equipment, and publicizing the results. In general, it was the responsibility of the $\mathrm{KCP}$ to perform cleaning efficacy measurements on sample panels and actual parts that were processed by ATC.

The cleaners chosen were evaluated for their abilities to remove the potential contaminants using an ultrasonic cleaning process at the KCP. The cleaning abilities of 20 different cleaners were compared to that of trichloroethylene, the baseline cleaning material. At least nine alternative cleaners produced cleaning results which exceeded trichloroethylene for this application. After evaluating the alternative cleaners and as new cleaning equipment was being tested, ATC terminated the Cooperative Agreement. Further equipment evaluations were suspended. 


\title{
PROJECT ACCOMPLISHMENT SUMMARY
}

\author{
Environmentally Conscious Closed-Loop Aqueous and Semi-Aqueous \\ Cleaning Systems for Defluxing and Degreasing
}

\section{BACKGROUND:}

American Technical Ceramics (ATC) Corporation, One Norden Lane, Huntington Station, New York, manufactures ceramic chip capacitors for the electronics industry. The Department of Energy (DOE), Kansas City Plant (KCP), is one of its many customers. (The KCP is operated by AlliedSignal Inc., Federal Manufacturing and Technologies for the United States Department of Energy under Contract No. DE-ACO476-DP00613.) ATC manufactures approximately 100,000 ceramic chip capacitors per day. Prior to this project, the KCP had previously worked with ATC on technology transfer aimed at eliminating its use of ozone-depleting cleaning solvents, primarily $1,1,1$ trichloroethane. $\mathrm{KCP}$ helped replace $1,1,1$ trichloroethane with a material that will comply with stratospheric ozone protection regulations. ATC uses cleaning solvents to remove rosin flux, tinning oil, and other general contaminants from its ceramic chip capacitors in a vapor degreasing cleaning process. They were especially interested in replacing trichloroethane prior to the May 15,1993 , Federally mandated labeling deadline. After this date, any product manufactured with class I ozone-depleting solvents, such as $1,1,1$ trichloroethane, was required to be identified with a label stating that the product was manufactured using an ozone-depleting chemical.

The KCP gave ATC recommendations for both short-term and long-term replacement options. Based upon tours of the ATC operation, discussions of its cleaning problems, considering its solvent preferences, and examining cleaning evaluations performed at $\mathrm{KCP}$, ATC was encouraged to pursue one of the chlorinated solvent options (particularly trichloroethylene). Orily the chlorinated solvents (trichloroethylene, methylene chloride, and perchloroethylene) are pure drop-in replacements for the vapor degreasing/ultrasonic cleaning process currently used at ATC. These solvents would give ATC the desired cleaning effectiveness and would be easy to recycle. ATC adopted this cleaning process to satisfy its need for a short-term solution to eliminate the ozone-depleting $1,1,1$ trichloroethane. This allowed ATC to avoid excessive capital equipment expenditures and meet the May 15, 1993, labeling deadline.

Since trichloroethylene and the other chlorinated solvents have undesirable health effects if overexposure occurs, are hazardous air pollutants, and are hazardous wastes, the KCP suggested that ATC consider alternate solvents, semi-aqueous cleaners and aqueous cleaners as long-term solutions to its current hazardous cleaning solvent situation. 
ATC expressed an interest in exploring those possible long-term solutions in a Cooperative Agreement with the KCP. The goal would be to develop an environmentally conscious cleaning process which would meet ATC's cleaning needs, reduce worker exposure to hazardous chemicals, and eliminate or reduce its hazardous waste. The KCP had ongoing studies regarding solvent substitution and had developed considerable knowledge in the field, especially the replacement of trichloroethylene. The vast array of cleanliness measurement equipment and expertise at $\mathrm{KCP}$ could be brought to bear to provide solutions for an alternative cleaning Cooperative Agreement as it had for traditional DOE production work.

\section{DESCRIPTION:}

The purpose of this project was to develop an environmentally conscious closed-loop cleaning process which would meet the cleaning needs of ATC, reduce worker exposure to hazardous chemicals, and eliminate or reduce its hazardous waste. In order to accomplish this, new cleaning materials needed to be tested for cleaning efficacy. Any new cleaner chosen must clean as well as or better than the currently used trichloroethylene. This cleaner must not be an ozone-depleting substance and must be less hazardous to worker's health than trichloroethylene. In addition, the cleaner must be able to be recycled and any rinse water used in the cleaning process must be recycled also. The cleaning material, cleaning equipment, and closed-loop equipment chosen must be able to work together effectively.

The project work plan was broken down into five phases. In general, it was the responsibility of the KCP to perform cleaning efficacy measurements on sample panels and actual parts that were processed by ATC. ATC supplied approximately 50,000 parts for testing, and the KCP supplied cleaned aluminum and copper panels for processing and testing.

The goal of Phase 1 of the project was to ascertain a baseline level of cleanliness for ATC's current cleaning process. Potential contaminants (intentional and unintentional) at ATC were identified by examining ATC's manufacturing processes. Cleaning evaluations were performed on panels purposely contaminated and then cleaned in trichloroethylene. Actual parts cleaned by ATC's current trichloroethylene cleaning process were also analyzed. Cleaning efficacy was determined quantitatively with analytical equipment by determining the amount of contaminants remaining on the item being tested. These methods included gas chromatography/mass spectrometry, Fourier Transform infrared analysis, residual rosin analysis, ohmegameter, Auger electron spectroscopy, and MESERAN surface analysis. 

Phase 2 of the project evaluated and screened alternate cleaners for their abilities to remove ATC's contaminants on a laboratory scale to determine which cleaners should be studied more extensively. Potential cleaners were identified through a literature search, general knowledge of cleaners available, and discussions with counterparts in the DOE weapons complex and industry. The cleaners chosen were evaluated for their abilities to remove the potential contaminants using an ultrasonic cleaning process at the KCP. The cleaning abilities of 20 different cleaners were compared to that of trichloroethylene, the baseline cleaning material. At least nine alternative cleaners produced cleaning results which exceeded trichloroethylene for this application. This phase generated a great deal of data regarding the removal of solder fluxes, a cleaning problem the entire electronics industry has to deal with. This information will be valuable not only to ATC or DOE but to industry in general.

Phase 3 of the project was intended to determine which combination of cleaner, cleaning equipment, and closed-loop equipment would best meet ATC's needs for an environmentally conscious closed-loop cleaning process. Cleaning equipment and equipment to close-loop the cleaning process were identified through a literature search, general knowledge of available closed-loop equipment, and visits to trade shows and vendors. One vendor's cleaning equipment was evaluated with three alternative cleaners selected from the set of nine which outperformed trichloroethylene in the screening tests of Phase 2. Both panels and actual ATC parts were run through an initial set of cleaning tests with one type of equipment at a vendor's location. Final cleaner and equipment selection was to be made after several of these evaluations were complete. At this point in the project, ATC terminated the Cooperative Agreement and further equipment evaluations ceased.

The goal of Phase 4 of the project was to have been implementation of the cleaner and equipment selection made in Phase 3 into ATC's facility. Specifications for the cleaning equipment and closed-loop equipment were to be written. The Cooperative Agreement called for ATC to purchase the cleaning equipment and for the KCP to purchase the closed-loop equipment. This equipment was to be purchased and installed in ATC's facility. Since these specifications had to be broadly written to allow competitive bids, the specification for the closed-loop equipment, KCP's responsibility, was already completed and awaiting cleaning equipment selection by ATC when the project was canceled. Closed-loop systems are directly dependent upon the cleaner and cleaning equipment chosen so it would have been inappropriate to proceed with the purchase of the closed-loop equipment without ATC's selection of cleaning equipment being known. The equipment costs for this portion of the project were estimated to be in the range of $\$ 100,000-\$ 150,000$ for the cleaning equipment to be purchased by ATC and approximately $\$ 50,000$ for the closed-loop recycling equipment that was to be purchased by the KCP. This portion of the project had been considered the most critical for overall project success. 
Phase 5 of the project was intended to publicize the work that had been performed and transfer this technology to interested parties. Within some limitations, this can still be accomplished as the information gathered applies to other DOE-related work.

Throughout the project, ATC personnel had high praise for the work performed at the $\mathrm{KCP}$. The data provided to them during the project, of course, relates directly to their operation and should be valid for many years. It is expected that it will be used by them when, at some point in the future, it becomes necessary for them to proceed with the purchase of cleaning equipment and the changeover to an alternative cleaning material.

\section{BENEFITS TO DOE:}

Environmentally conscious cleaning is a key technology to future Defense Programs (DP). This technology is currently being instituted throughout the DOE Weapons Complex, and the DOE KCP is at the forefront of this emerging technology. The KCP has design laboratory Process Capability Assurance Program (PCAP) guidance relating to elimination of ozone-depleting solvents, self-contained cleaning systems, pollution prevention, waste minimization, elimination of carcinogens, and reduction and/or elimination of volatile organic compounds (VOCs) for future DP responsibilities. These are all benefits of environmentally conscious cleaning. The processes and techniques investigated in this project are similar to those practiced in support of DP responsibilities. In addition, the knowledge gained from this work is directly applicable to future weapons and non-weapons-related activities because environmentally conscious cleaning processes must be used in the future regardless of what is being manufactured in the private and/or government sectors. The cleaning material data generated in this work is directly and immediately applicable to the electronics industry. This project, therefore, directly supports the DOE PCAP requirements, the intent of DOE's Technology Transfer Initiative, DOE DP, and future non-weapons-related activities.

\section{ECONOMIC IMPACT:}

This project has improved the financial position of our partner by not having to fund the complete program alone and still gaining valuable information from technology transfer. Reduced costs for purchase of hazardous materials and the costs for disposal of hazardous waste materials will be a major benefit for our partner. The technology gained from this project can be spun off to other manufacturers of ceramic chip capacitors and other electronic components. In addition, this technology will also be useful to all manufacturers who clean after soldering or who have to remove oils and other general contaminants (i.e., the entire electronic industry and a good portion of the mechanical industry could use this information). This technology will increase the competitiveness of the U.S. electronic industry and potentially the U.S. mechanical industry. Estimates for the size of markets immediately impacted are $\$ 2.65$ billion/year for the capacitor 
industry, $\$ 55.2$ billion/year for the passive components industry, and $\$ 271$ billion/year for the electronic industry.

U.S. workers will be helped by this technology because the cleaners are less hazardous than those currently being used; therefore, workers' exposure to hazardous chemicals will be reduced. In addition, U.S. workers will benefit because a reduction in purchase and disposal of hazardous chemicals, reduction in cost to evaluate and implement alternate cleaning processes, and increased competitiveness will result in more jobs. By developing an economically competitive, environmentally conscious method of cleaning components, more jobs will be kept in the U.S. because companies will not have an economic reason to ship this work out of the country where less stringent environmental regulations exist. Consumers ultimately benefit from both the environmental attractiveness and reduced overall costs associated with alternative cleaning materials. This project supports the nationally defined critical technology of Pollution Minimization, Remediation, and Waste Management in the area of Energy and Environment.

PROJECT STATUS: Terminated. 


\section{DOE FACILITY POINT(S) OF CONTACT FOR PROJECT INFORMATION:}

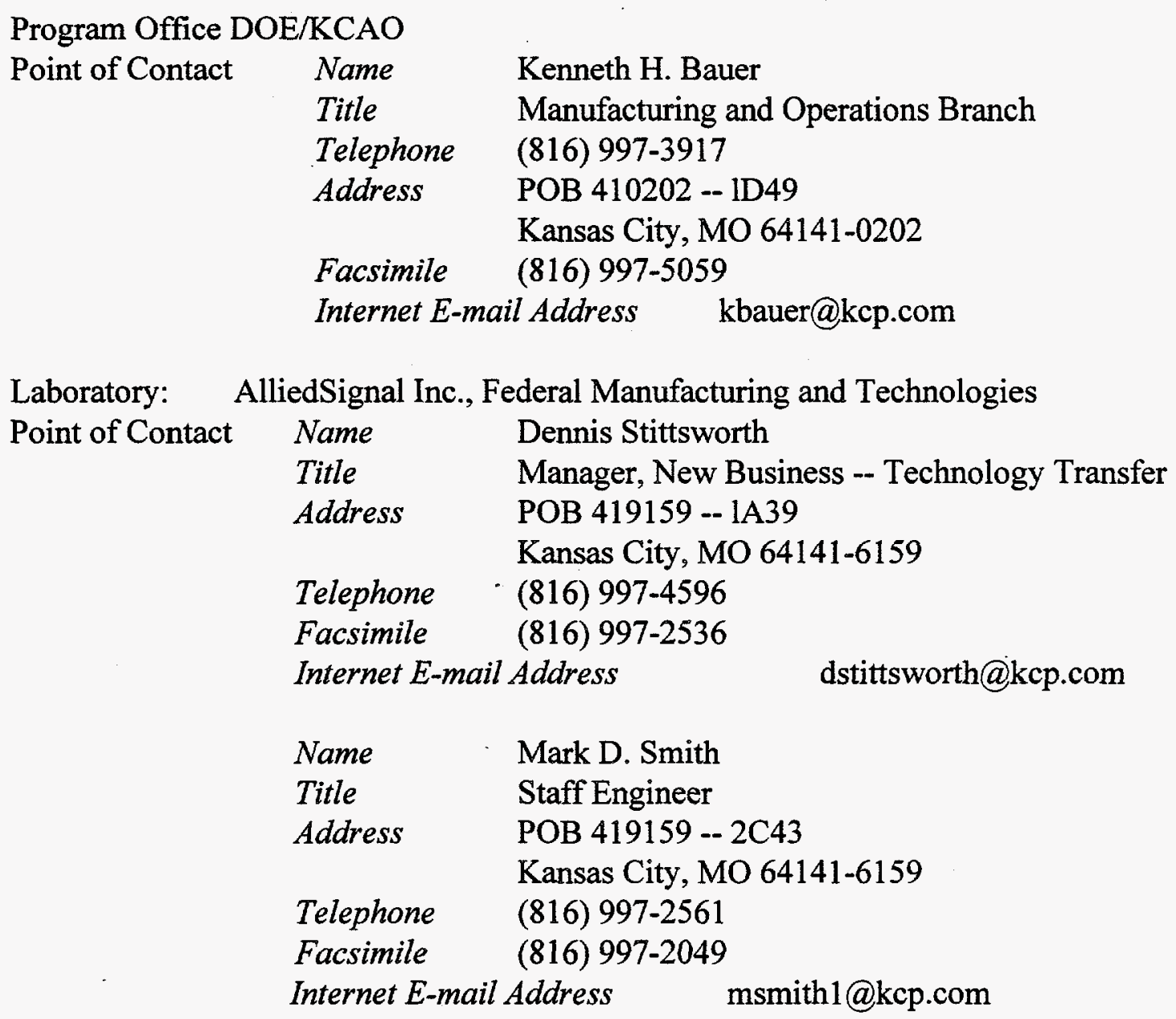

\section{COMPANY SIZE AND POINT(S) OF CONTACT:}

Non-Federal Participant(s)

Organization Name

Type

Point of Contact

\author{
American Technical Ceramics Corporation \\ Small Business \\ Huntington Station, NY 11726-2102
}

Name Salvatore Laona

Title Director of Design Engineering

Address One Norden Lane

Telephone (516) 547-5762

Facsimile (516) 547-5742

Contact Salvatore Laona for feedback regarding the success of the project. 


\section{PROJECT EXAMPLES:}

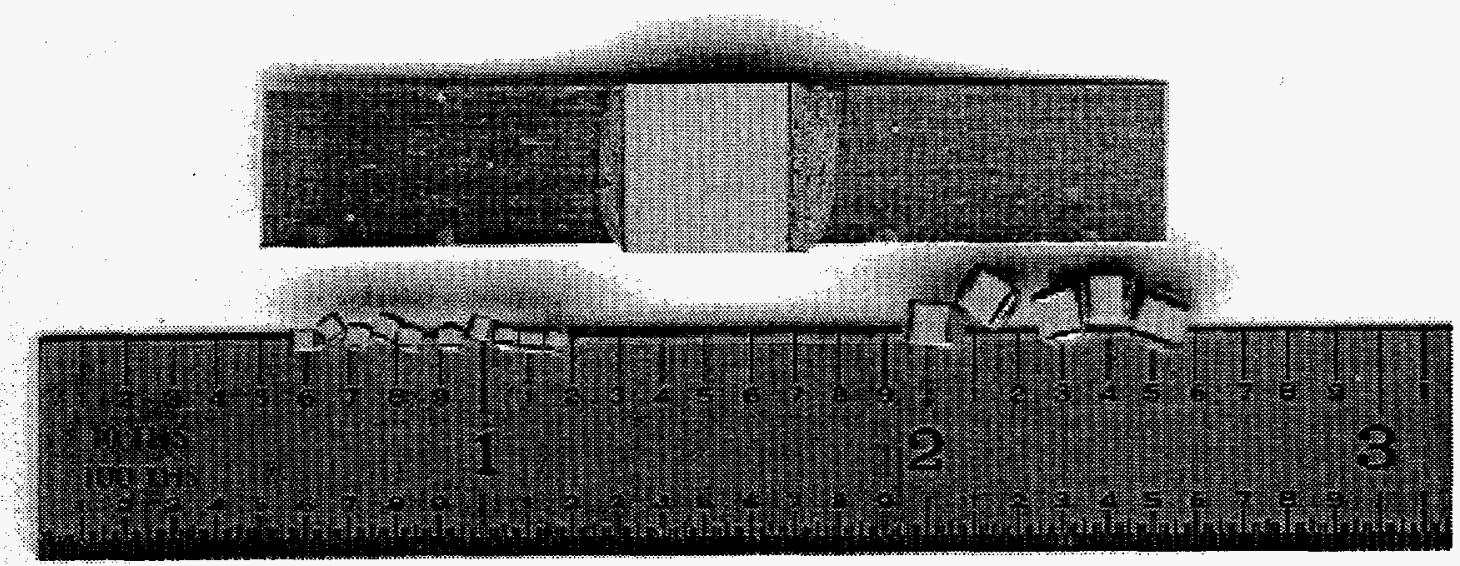

Figure 1. Examples of the size range of ceramic capacitors manufactured by ATC and test cleaned during this project. (Scale is in inches.)

A table of MESERAN Surface Analysis data for 18 of the 20 alternate cleaners or solvents and trichloroethylene is given in Table 1. (Two of the solvents tested were so ineffective in cleaning even the easiest to remove contaminants that further testing with them would have been meaningless.) This table summarizes cleaning efficacy as measured with the MESERAN Surface Analyzer using evaporative rate analysis. In this analysis, lower numbers indicate lower amounts of contaminants left on the surface after cleaning. Data is shown for each contaminant and each cleaner. An average of all the tests for each cleaner is given along the bottom row of the table. The table shows that for this type of cleaning application several solvents yielded cleaner surfaces than did trichloroethylene. This information should be directly applicable to any operation attempting to remove solder fluxes (and the few general contaminants listed at the top of the table) from ceramic capacitors or other individual parts. Compatibility testing should be considered with some of the solvents listed when cleaning populated printed circuit boards or other items where certain polymers, adhesives, or inks may come in contact with the solvent. 

Table 1. Solvent Screening MESERAN Results

\begin{tabular}{|c|c|c|c|c|c|c|c|c|c|c|c|c|c|c|c|c|c|c|c|}
\hline SOLVENT $\rightarrow$ & EC.7R & EC-ULTRA & EXXATE 1000 & IKN1 2000 & G10.T max & BIO-T 200A & SYMERGY 3000 & THFA & ARMAKLEEN 2001 & ARMAKLEEN 2002 & MMP & PAEPSOLV & IONOX FCR & EC-7M & KA11 & AXAREL 2200 & AXAPEL 36 & OXSOL 253 & TRICHLOR \\
\hline CONTAMINANT & & & & & & & & & & & & & & & & & & & \\
\hline FNGEROLL & 0 & 2 & 0 & 2 & 18 & 14 & 29 & 0 & 51 & 41 & 3 & 8 & 93 & 27 & 2 & 8 & 2 & 11 & 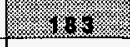 \\
\hline LUBRIDEFM & 14 & 4 & 43 & 9 & 19 & 7 & 41 & 19 & 17 & 53 & 72 & 10 & 1888 & 1 & 0 & 43 & 11 & 18 & 8 \\
\hline LMAON. & 10 & 0 & 14 & 0 & $7^{\circ}$ & 1 & 11 & 0 & 31 & 62 & 1 & 0 & 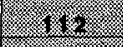 & 6 & 32 & 11 & 14 & 29 & 12 \\
\hline MEIEX & 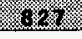 & 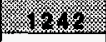 & 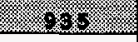 & (2) & 1.80 & 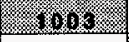 & 54 & 17 & 1.1 .6$. & 1298 & 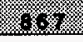 & 8.80 & 80 & 1.1. & 1212 & $\sqrt{148}$ & 804 & 976 & 1.282 \\
\hline & & & & & & & & & & & & & & & & & & & \\
\hline
\end{tabular}

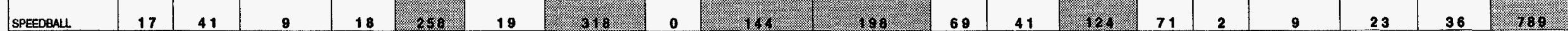

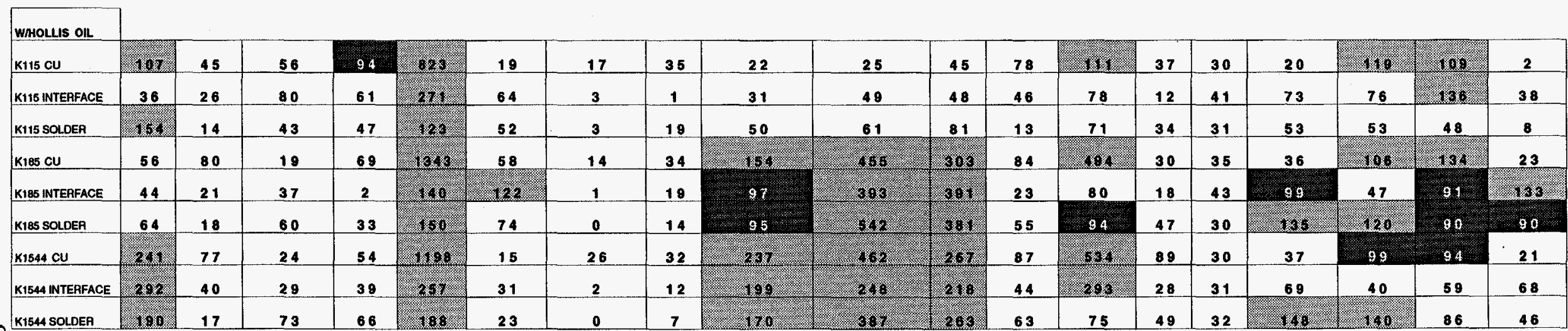

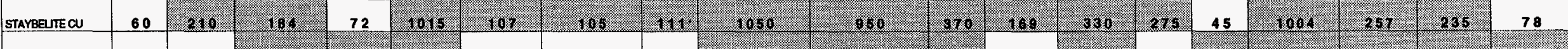

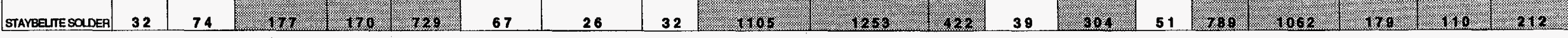

\begin{tabular}{|c|c|c|c|c|c|c|c|c|c|c|c|c|c|c|c|c|c|c|c|}
\hline HAND DIP & & & & & & & & & & & & & & & & & & & \\
\hline K115 CU & 38 & 63 & 17 & 45 & 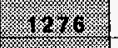 & 37. & 30 & 34 & 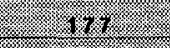 & 1.162. & 68 & 83 & 178 & 50 & 34 & 50 & 2.00 & 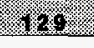 & 66 \\
\hline K115 INTERFACE & 32 & 34 & 15 & 18 & 960 & 40 & 2 & 9 & 2.00 & 20.0 & 79 & 42 & 2.2 .32 & 36 & 37 & 8 & 51 & 60 & 17 \\
\hline K115 SOLDER & 8 & 41 & 13 & 4 & 2,48 & 3 & 1 & 13 & 87 & 93 & 8,80 & 8 & 92 & 20 & 20 & 63 & 94 & 64 & 57 \\
\hline$K 185 \mathrm{CU}$ & 33 & 1009 & 25 & 42 & 210 & 41 & 25 & 20 & $1 / 13$ & (36.5. & 1.180 & 1.15 & 1012 & 39 & 82 & 77 & 99 & 178 & trog. \\
\hline K185 INTERFACE & 34 & 48 & 42 & 6 & 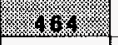 & 29 & 3 & 2 & 2858: & 202 & 100 & 13 & 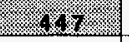 & 38 & 32 & 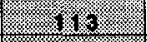 & 61 & 52 & 34 \\
\hline K185 SOLDER & 36 & 45 & 28 & 82 & 63 & 6 & 0 & 1 & 2.16 & 252 & 98 & 53 & 76 & 47 & 19 & 128 & 118 & 89 & 2 \\
\hline K1544 CU & 32 & 62 & 11 & 36 & 2,160 & 35 & 31 & 16 & $2.1 / 28$ & 483 & 1.28. & 82 & .863. & 36 & 37 & 83 & $\sqrt[3]{2}$ & 134 & 106 \\
\hline K1544 INTERFACE & 59 & 21 & 15 & 25 & $2.22 \%$ & 34 & 9 & 17 & 88 & 8.92 & 1.98 & 48 & 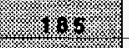 & 69 & 50 & 10.17. & 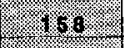 & 85 & 12 \\
\hline K1544 SOLDER & 7 & 68 & 56 & 44 & 10 & 0 & 5 & 8 & 48 & 167 & 12864 & 35 & 1.100 & 40 & 41 & $1=152$ & 152 & 64 & 19 \\
\hline 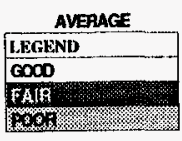 & 97 & 96 & 80 & 79 & 435 & 76 & 30 & 19 & 240 & 354 & 205 & 73 & 327 & 92 & 110 & 169 & 126 & 125 & 137 \\
\hline
\end{tabular}


, 


\section{TECHNOLOGY COMMERCIALIZATION:}

Phase 5 of the project was intended to publicize the work that had been performed and transfer this technology to interested parties. Since the project was terminated and funding for the project stopped, the extensive transfer of the data that was planned is not anticipated. Within some limitations, transfer can still be accomplished as the information gathered applies to other DOE-related work or under separate funding sources. Substantially more data than is given in this final report is available from the AlliedSignal contacts. 
